\title{
Appropriateness Assessment of Infrastructure Distribution for Disaster Response by Local Governments
}

\author{
Youn-Ha Lee ${ }^{1}$, Dong-Min Seo ${ }^{2}$ and Won-Hwa Hong ${ }^{3}$
}

\begin{abstract}
In Korea, the damage caused by water disasters occurs every year, and $\$ 426$ million of average annual damage has occurred due to typhoons and heavy rainfall in the last 10 years. Therefore, although various infrastructure facilities are installed to prepare for and respond to water disasters, there is a significant regional variation in the current situation, and there is little national research to efficiently allocate infrastructure using limited resources. The purpose of this study is to evaluate the appropriateness of the installed infrastructure in each local government and derive vulnerable areas for the disaster response.

The possibility of water disaster was classified based on the characteristics of rainfall and water disaster and the installation status of disaster response infrastructure was classified in consideration of flood safety. Also, by summarizing these, a proposal for evaluating the appropriateness of the infrastructure in local governments was proposed.
\end{abstract}

Keywords-Disaster, Infrastructure, Local government, Characterization, etc.

\section{INTRODUCTION}

As urban environments become more sophisticated, complex, and stereotyped throughout the world, the uncertainties of potential risks from disasters, crimes and infectious diseases and the possibility of a series of disasters are increasing.[1] Especially in Asia, the damage caused by drought and water disasters occurs annually and in Korea, \$426million of average annual damages has occurred due to typhoon and heavy rain for the last 10 years. Currently, the government of the Republic of Korea is pursuing national affairs such as 'strengthening the overall national disaster management system', 'adaptation to climate change such as extreme weather', and 'development of the country in harmony with the environment according' in accordance with the national public security strategy. Accordingly, from 2015, the local safety index is calculated to diagnose regional safety and efforts are made to improve the safety of vulnerable areas. However, in the case of the regional safety index, it is divided into risk indicators (number of deaths or accidents), vulnerable indicators (weighted risk indicators), and mitigation indicators (mitigation of hazard indicators) and

\footnotetext{
${ }^{1}$ Doctor's Course, School of Architectural, Civil, Environmental and Energy Engineering, Kyungpook National University

${ }^{2}$ Master's Course, School of Architectural, Civil, Environmental and Energy Engineering, Kyungpook National University

${ }^{3}$ Professor, School of Architectural, Civil, Environmental and Energy Engineering, Kyungpook National University
}

is calculated according to the formula so that If the safety index is high, it can be interpreted as meaning that the number of deaths per 10,000 people in each field (the number of cases in case of crime and safety accidents) is relatively low and it is practically safe compared to other regions [2], but realistically, it would be difficult to directly utilize it to supplement the vulnerable parts of each local government. Therefore, this study aims to identify water hazard vulnerability of local governments and evaluate the appropriateness of the infrastructure installation for the disaster response by the local governments so that it can be used to cope with those vulnerabilities.

\section{METHODS}

This study limited a scope of the study to water disaster which is the most damaging natural disasters in Korea and in order to evaluate the appropriateness of the infrastructure installation for the disaster response by the local governments, it was proceeded in the following sequence of study.

1) Investigation of water disaster status and response intrastate

2) Analysis of disaster occurrence characteristics and distribution of responding infrastructures by local governments

3) Classification of disaster occurrence status by local government

4) Classification of responding infrastructure facility distribution status by local government

5) Appropriateness assessment of disaster response infrastructure distribution by local government

This study divided the local administrative units into city( $\mathrm{Si})$ and county $(\mathrm{Gu})$ which are the largest administrative units in Korea, by the problem of securing statistics and related data.

There are ways to classify grades such as equal interval and quantile. The equal interval is a method of classifying at the same interval, and the quantileis a method of classifying at the same rate. On the other hand, in Natural Break (Jenks), it arbitrarily divides grades and then while repeatedly calculating the average and deviation, it repeats the operation of adjusting the grade of the object one by one until the optimized value is satisfied.[3] The method applied in this study is Natural Break (Jenks), which is a method to subjectively classify data compared to the equal interval or the quantile, however since the purpose of this study is a direct comparison of characteristics of each local government, it was judged to be 
more appropriate than the equal interval or the quantile to explain actual phenomenon.

\section{APPROPRIATENESS ASSESSMENT OF INFRASTRUCTURE INSTALLATION FOR WATER DISASTER RESPONSE}

3.1 Classification of disaster situation by local governments
Per the 2015 disaster yearbook, damages caused by natural disasters occurred in Korea in the last 10 years amounted to $\$$ 456.5 million, of which the damage caused by heavy rains and typhoons accounted for $65 \%$ and $28 \%$, respectively. A total of 218 people were killed and 196,697 people became victims in the last 10 years, and by number, annually, an average of 22 people were killed or missing due to water disaster and 19,670 victims occurred.

TABLE I: DAMAGE DUE TO WATER DISASTERS IN RECENT 10 YEARS[4]

\begin{tabular}{|c|c|c|c|c|c|c|c|c|c|c|c|c|}
\hline Classification & 2006 & 2007 & 2008 & 2009 & 2010 & 2011 & 2012 & 2013 & 2014 & 2015 & Total & Average \\
\hline Death \& Missing (person) & 63 & 17 & 11 & 13 & 14 & 78 & 16 & 4 & 2 & 0 & 218 & 22 \\
\hline Victims (person) & 2,883 & 675 & 4,627 & 11,931 & 76,110 & 10,099 & 18,356 & 4,233 & 7,691 & 92 & 196,697 & 19,670 \\
\hline Flooded area (ha) & 34,759 & 4,859 & 602 & 5677 & 12,925 & 14,892 & 487 & 0 & 89 & 0 & 74,290 & 7,429 \\
\hline
\end{tabular}

Water disaster status can be generally assessed by property damage, loss of life or flooding area. In addition, the designation status of the natural disaster risk zone, the declaration status of the special disaster area, and the incidence rate of serious damage are items that can evaluate the risk of water disaster in the area.

In this study, the status of water disaster in each municipality was graded by using statistical data related to water disaster status, which was constructed by each local government and the following table lists the data used for this purpose. 9 variables were used for the classification, and the average value of each grade was calculated and re-classified to derive the regional grade per the occurrence of the disaster. The results are graded from small sequentially, and the higher the grade, the higher the probability of water disaster.

TABLE II : .LIST OF DISASTER OCCURRENCE STATISTICS BY LOCAL GOVERNMENT

\begin{tabular}{|c|c|c|c|}
\hline Classification & Category & Unit & Source \\
\hline $1 \mathrm{st}$ & $\begin{array}{l}\text { Natural Hazard Danger Zone (Flooding } \\
\text { risk) Designation status }\end{array}$ & Location(s) & $\begin{array}{l}\text { Ministry of Government Administration and } \\
\text { Home Affairs (local news) }\end{array}$ \\
\hline 2nd & $\begin{array}{l}\text { Proclamation status of special disaster } \\
\text { area }\end{array}$ & Location(s) & Disaster yearbook \\
\hline 3rd & Incidence rate of serious damage & $\begin{array}{l}\text { Frequency, } \\
\text { average amount of damage }(\$)\end{array}$ & Disaster yearbook \\
\hline 4 th & \multirow{4}{*}{ Status of typhoon and heavy rain damage } & Casualties(person(s)) & Disaster yearbook \\
\hline 5 th & & Victims(person(s)) & Disaster yearbook \\
\hline 6th & & Flooded area(ha) & Disaster yearbook \\
\hline 7 th & & Damage recovery cost $(\$)$ & Disaster yearbook \\
\hline 8 th & $\begin{array}{l}\text { Average annual } \\
\text { precipitation }\end{array}$ & Precipitation $(\mathrm{mm})$ & Meteorological office \\
\hline 9th & Ratio of Impervious Surface & Percentage $(\%)$, area $\left(\mathrm{km}^{2}\right)$ & Land cover, Ministry of Environment \\
\hline
\end{tabular}

3.2 Classification of responding infrastructure by local governments

In the case of river facility, it refers to a facility to control the river water level such as dams, canals, reservoirs, drainage pumping stations and in this study, it is a comprehensive facility including multiple infrastructures selected. However, in the case of statistical data provided by national authorities, the number of facilities, expansion, and area of river facilities are provided so that there is a difficulty in standardization for direct comparative evaluation by local governments. Therefore, among the facilities included in the river facility, lagoons, reservoirs, drainage pumping stations, etc. were additionally evaluated and infrastructure to be evaluated is shown in the following table.

In order to quantify the disaster response capacity of the infrastructure, standardization of each local government 's area or value per population level has been made to classify the response capability of each infrastructure as shown in the following table. The results are graded from small sequentially, and the higher the grade, the more the infrastructure is installed and the more disaster-friendly the area is. 
TABLE III : LIST OF DISASTER OCCURRENCE STATISTICS BY LOCAL GOVERNMENT

\begin{tabular}{|c|c|c|c|c|c|c|c|c|c|c|}
\hline Classification & $1 \mathrm{st}$ & 2 nd & $3 \mathrm{rd}$ & 4 th & 5 th & 6th & 7 th & 8th & 9th & Average \\
\hline Seoul & 2 & 2 & 4 & 4 & 5 & 4 & 1 & 4 & 5 & 3.44 \\
\hline Busan & 2 & 2 & 2 & 2 & 3 & 2 & 2 & 5 & 4 & 2.67 \\
\hline Daegu & 1 & 1 & 1 & 1 & 1 & 1 & 1 & 2 & 4 & 1.44 \\
\hline Incheon & 1 & 1 & 1 & 2 & 4 & 1 & 1 & 2 & 4 & 1.89 \\
\hline Gwangju & 1 & 2 & 2 & 1 & 1 & 1 & 1 & 3 & 4 & 1.78 \\
\hline Daejeon & 1 & 1 & 1 & 1 & 1 & 1 & 1 & 4 & 4 & 1.67 \\
\hline Ulsan & 1 & 2 & 3 & 2 & 1 & 1 & 1 & 2 & 3 & 1.78 \\
\hline Sejong & 1 & 1 & 1 & 1 & 1 & 1 & 1 & 1 & 2 & 1.11 \\
\hline Gyeonggi & 2 & 4 & 3 & 5 & 5 & 5 & 4 & 3 & 3 & 3.78 \\
\hline Gangwon & 3 & 4 & 5 & 5 & 2 & 1 & 5 & 4 & 1 & 3.33 \\
\hline Chungcheongbuk-do & 3 & 3 & 2 & 2 & 1 & 1 & 2 & 2 & 1 & 1.89 \\
\hline Chungcheongnam-do & 3 & 3 & 2 & 2 & 2 & 3 & 3 & 2 & 2 & 2.44 \\
\hline Jeollabuk-do & 4 & 4 & 2 & 3 & 3 & 4 & 3 & 3 & 2 & 3.11 \\
\hline Jeollanam-do & 4 & 5 & 3 & 3 & 3 & 3 & 4 & 3 & 1 & 3.22 \\
\hline Gyeongsangbuk-do & 5 & 3 & 3 & 3 & 2 & 2 & 3 & 2 & 1 & 2.67 \\
\hline Gyeongsangnam-do & 4 & 5 & 3 & 3 & 2 & 5 & 4 & 5 & 2 & 3.67 \\
\hline Jeju-do & 3 & 2 & 5 & 3 & 1 & 3 & 2 & 5 & 2 & 2.89 \\
\hline
\end{tabular}

TABLE IV: ASSESSMENT LIST OF INFRASTRUCTURE WATER DISASTER RESPONSE CAPABILITY BY LOCAL GOVERNMENT

\begin{tabular}{c|c|l|l}
\hline \hline Classification & Category & \multicolumn{1}{c}{ Standardization } & \multicolumn{1}{c}{ Unit } \\
\hline 1st & River facility & Area/ Area of Local government & $\mathrm{m}^{2} / \mathrm{km}^{2}$ \\
\hline 2nd & Lagoon & Capacity/ Area of Local government & $\mathrm{m}^{3} / \mathrm{km}^{2}$ \\
\hline 3rd & Reservoir(dam) & Capacity/ Area of Local government & $1000 \mathrm{ton} / \mathrm{km}^{2}$ \\
\hline 4th & Reservoir(levee) & Area/ Area of Local government & $\mathrm{m}^{2} / \mathrm{km}^{2}$ \\
\hline 5 th & Drainage pumping station & Water capacity/Area of Local government & $\mathrm{m}^{3} / \mathrm{min}^{2} \mathrm{~km}{ }^{2}$ \\
\hline 6 th & Rainwater utilization facility & Storage capacity/Area of Local government & $\mathrm{m}^{3} / \mathrm{km}^{2}$ \\
\hline 7 th & Manhole & Number of locations/Area of Local government & $\mathrm{number} / \mathrm{km}{ }^{2}$ \\
\hline 8th & Pipeline & Length/Area of Local government & $\mathrm{m} / \mathrm{km}$ \\
\hline 9th & Temporary housing facility & Housing capacity/Local population & $\mathrm{people} / \mathrm{people}$ \\
\hline \hline
\end{tabular}

3.3 Appropriateness of infrastructure installation for disaster response by local government

In general, flood analysis model is used to predict local flood risk. However, in this study, the possibility of flood disaster is graded based on rainfall characteristics and water disaster status to evaluate appropriateness of infrastructure installation of each local government. In addition, the installation status of water-related disaster response infrastructure considering safety was graded.
The probability of water disaster is negative, and the installation status of the infrastructure is set to $(+)$ value, and the appropriateness of the installation is evaluated by adding them and its result is shown in the following figure.

The results are graded from small sequentially, and the lower the grade, the more areas where disaster response infrastructure needs to be installed. 
TABLE V : STATUS OF INFRASTRUCTURE BY ASSESSMENT ITEM

\begin{tabular}{|c|c|c|c|c|c|c|c|c|c|c|}
\hline Classification & $1 \mathrm{st}$ & 2nd & $3 r d$ & 4th & 5 th & 6th & 7 th & 8 th & 9th & Average \\
\hline Seoul & 5 & 5 & 1 & 1 & 5 & 4 & 4 & 5 & 3 & 3.67 \\
\hline Busan & 1 & 3 & 1 & 1 & 4 & 2 & 2 & 4 & 1 & 2.11 \\
\hline Daegu & 2 & 4 & 3 & 1 & 4 & 2 & 2 & 4 & 1 & 2.56 \\
\hline Incheon & 2 & 5 & 1 & 1 & 3 & 3 & 2 & 3 & 2 & 2.44 \\
\hline Gwangju & 4 & 3 & 1 & 1 & 3 & 1 & 3 & 4 & 2 & 2.44 \\
\hline Daejeon & 3 & 1 & 1 & 1 & 1 & 1 & 2 & 4 & 2 & 1.78 \\
\hline Ulsan & 1 & 2 & 1 & 2 & 3 & 1 & 2 & 3 & 5 & 2.22 \\
\hline Sejong & 3 & 2 & 1 & 1 & 2 & 1 & 1 & 1 & 3 & 1.67 \\
\hline Gyeonggi & 3 & 2 & 4 & 1 & 3 & 2 & 5 & 2 & 2 & 2.67 \\
\hline Gangwon & 3 & 1 & 1 & 1 & 1 & 1 & 1 & 1 & 5 & 1.67 \\
\hline Chungcheongbuk-do & 3 & 1 & 1 & 3 & 1 & 1 & 1 & 1 & 4 & 1.78 \\
\hline Chungcheongnam-do & 3 & 1 & 1 & 4 & 1 & 1 & 1 & 1 & 4 & 1.89 \\
\hline Jeollabuk-do & 3 & 2 & 1 & 1 & 1 & 1 & 1 & 1 & 3 & 1.56 \\
\hline Jeollanam-do & 3 & 2 & 3 & 1 & 1 & 1 & 1 & 1 & 4 & 1.89 \\
\hline Gyeongsangbuk-do & 3 & 1 & 2 & 1 & 1 & 1 & 1 & 1 & 4 & 1.67 \\
\hline Gyeongsangnam-do & 2 & 2 & 5 & 5 & 2 & 1 & 1 & 1 & 4 & 2.56 \\
\hline Jeju-do & 1 & 1 & 1 & 1 & 1 & 5 & 1 & 2 & 1 & 1.56 \\
\hline
\end{tabular}

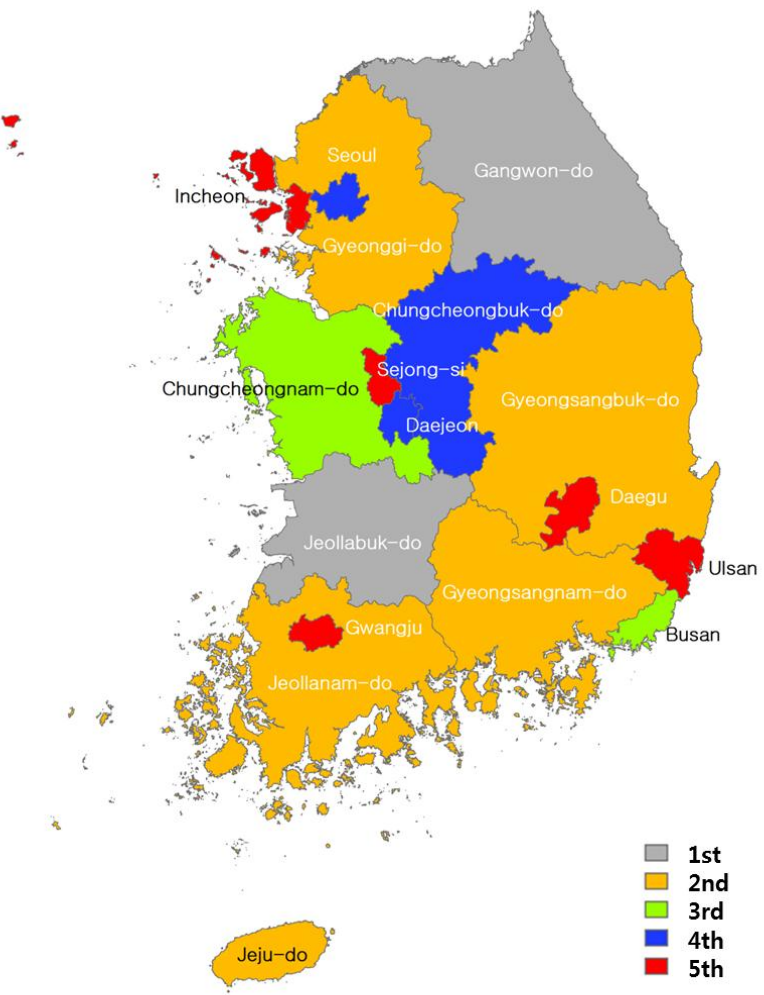

Fig. 1: Safety assessment for disaster response by local governments 


\section{IV.CONCLUSION}

In Korea, since 2015, the local safety index has been calculated to diagnose regional safety and efforts are being made to improve the safety of vulnerable areas. For the local safety index, if the safety index is high, it can be interpreted to mean that the number of deaths per 10,000 population by sector (the number of cases in case of crime and safety accidents) is less and it is relatively safe compared to other regions, however it would be difficult to directly utilize it to supplement the vulnerable parts of each local government. Therefore, this study aimed to evaluate the appropriateness of the installed infrastructure to cope with the disaster in each local government and derive vulnerable areas.

The possibility of water disaster was classified based on the characteristics of rainfall and water disaster and the installation status of disaster response infrastructure was classified in consideration of flood safety. Also, by summarizing these, a proposal for evaluating the appropriateness of the infrastructure in local governments was proposed.

Classification was implemented by Natural Break(Jenks) and per the result of classifying into 5 levels, it was possible to derive the local governments that need to expand the water disaster response infrastructure compared to other local governments.

Although this study did not present quantitative requirements for each local government infrastructure, there is a significance that it can provide basic data on priorities and planning decisions when expanding the infrastructure by utilizing limited resources of the whole country.

Also, as there is a limitation such as that it does not consider the importance or level of influence of each influence factor, it will be necessary to supplement it later.

\section{ACKNOWLEDGEMENT}

This research was supported by a grant (16AWMP-B079625-03) from Water Management Research Program funded by Ministry of Land, Infrastructure and Transport of Korean government.

\section{REFERENCES}

[1] National Disaster Management Institute, "Development of Evaluation and Diagnosis Methods of Safer City", 2013.

[2] Ministry of Public Safety and Security, "Regional Safety Index Classes Calculation · Public open Q\&A", 2015.

[3] http://pro.arcgis.com/en/pro-app/ (2017.1.17.)

[4] Ministry of Public Safety and Security, "2015 STATISTICAL YEARBOOK OF NATURAL DISASTER”, 2015.

[5] National Disaster Management Institute, "Establishment of Capacity Analysis Method and Risk Register for Local Safety Management", 2015.

[6] National Disaster Management Institute, "Analysis of Interdependencies and Cascading Failure Effects on Critical Infrastructure", 2013.

[7] National Disaster Management Institute, "Study of the Countermeasures on Extreme Flood", 2009.

[8] Korea Research Institute for Human Settlements, "A Study on Improvement of the Urban Flooding Disaster Prevention System coped with Climate Change", 2013.

[9] Oh, Tae Suk and Moon, Young Il, "Effect Analysis of Precipitation Events According to an Urbanization”, JOURNAL OF THE KOREAN
SOCIETY OF CIVIL ENGINEERS, vol.30, No.4, pp.413 427, July 2010.

[10] Song, Min Kyung and Chang, Hoon, "Characterization of Cities in Seoul Metropolitan Area by Cluster Analysis", Journal of the Korean Society for Geo-Spatial Information System, vol.18, No.1, pp. 83 88, March 2010.

[11] https://www.hasudoinfo.or.kr

[12] http://www.safekorea.go.kr/idsiSFK/index_web.jsp

[13] https://www.laiis.go.kr/jsp/cmm/main/MainIndex_02.jsp

[14] http://www.kma.go.kr/index.jsp

[15] http://webhelp.esri.com 